\title{
"Los herederos de la Reforma" El Movimiento Nacional Reformista (MNR) y la tradición reformista argentina
}

\author{
"The heirs of the University Reform" \\ The National Reform Movement (MNR) \\ and the argentine reformist tradition
}

\author{
Fernando Manuel Suárez \\ Centro de Estudios Históricos \\ Universidad Nacional de Mar del Plata \\ fermsuarez@gmail.com
}

(Argentina)

\section{Resumen}

En este artículo analizaremos la experiencia del Movimiento Nacional Reformista (MNR), organización estudiantil que sirvió de semillero de los que luego sería el Partido Socialista Popular, en especial el modo en que esta agrupación adoptó el discurso reformista y lo articuló para dar forma a una identidad política relativamente estable y sostenida en el tiempo. Para ello, indagaremos, en primer lugar, los rasgos distintivos del MNR en su proceso de constitución y consolidación en la década del sesenta: sus orígenes, sus principales dirigentes y sus vectores ideológicos. Luego, en segunda instancia, repasaremos la "tradición reformista" recuperada por el MNR, sus líneas programáticas, sus referentes intelectuales y su proyecto político-ideológico, y de qué modo sirvió de pivote para su articulación identitaria. En tal sentido, veremos cómo el reformismo se constituyó en una referencia nodal en la configuración del MNR y en su derrotero posterior, una marca distintiva, con cierto potencial político, en tiempos donde primaba la radicalización política y la revitalización del peronismo.

Palabras Clave: Reforma Universitaria, tradición reformista, Movimiento Nacional Reformista, identidades políticas 


\begin{abstract}
In this article we will analyze the experience of the National Reform Movement (MNR), a student organization that served as the seedbed of what would later become the Popular Socialist Party (PSP), especially the way in which this group adopted the reformist discourse and articulated it to shape a relatively stable political identity that sustained over time. In order to do so, we will first investigate the distinctive features of the MNR in its process of constitution and consolidation in the 1960s: its origins, its main leaders and its ideological vectors. Then, in second instance, we will review the "reformist tradition" as it were recovered by the MNR, its programmatic lines, its intellectual referents and its political-ideological project, and how it served as an identity focus. In this sense, we will see how reformism became a nodal reference in the configuration of the MNR and in its subsequent course, a distinctive mark, with a certain political potential, in times where political radicalization and the revitalization of Peronism prevailed.
\end{abstract}

Keywords: University Reform, Reformist tradition, National Reform Movement, political identities

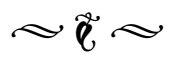

\section{Introducción}

El objetivo de este artículo es indagar el reformismo universitario desde una perspectiva diferente, que no pondrá el foco estrictamente en los acontecimientos de 1918 ni en sus efectos más inmediatos, sobre lo cual ya existe una muy cuantiosa bibliografía. ${ }^{1}$ En contraste, nos centraremos en el reformismo universitario en tanto tradición política y su carnadura identitaria en la constitución de una organización política específica varias décadas después: el Movimiento Nacional Reformista (en adelante, MNR). ${ }^{2}$

Esto implica pensar a la reforma y el reformismo no como un acontecimiento pretérito pa-

1. Incluso, más allá de los muchos trabajos de investigación, ya existen obras de síntesis y divulgación sobre este proceso, como por ejemplo Bustelo (2018).

2. Este artículo forma parte de una investigación más amplia dedicada a los orígenes del Partido Socialista Popular, cuyo antecedente organizativo directo es el MNR. Véase Suárez (2018). sible de ser descripto y analizado objetivamente, sino como un proceso histórico sometido a diferentes operaciones de reinterpretación y reactualización selectiva por parte de actores específicos, en diálogo con las propias fuentes y en discusión con otras interpretaciones en pugna. En ese sentido, el reformismo universitario ni surgió estrictamente en Córdoba en 1918, ni mucho menos se extinguió allí. Fue un fenómeno de por lo menos escala continental (aunque sus repercusiones fueron incluso más allá $)^{3}$ y cuya proyección en el tiempo, como ideario y programa, ha llegado prácticamente hasta nuestros días, no sin algunas transformaciones mediante.

El reformismo universitario articuló desde sus comienzos un programa que abarcaba distintos órdenes y escalas de acción. Por un lado, el reformismo universitario proponía, como se deduce con facilidad, un conjunto de transformaciones concretas para las instituciones de

3. Ver Halliday (1970). 
educación superior universitaria relacionadas, entre otros aspectos, con las condiciones de acceso, la transparencia en los procedimientos de selección del cuerpo docente, y la participación del claustro estudiantil en el gobierno de la institución. En segundo lugar, el reformismo proponía algunos ejes articuladores, más vagos que los primeros, con respecto a la política nacional y continental, con un marcado énfasis en el tópico antiimperialista -más estrictamente, antinorteamericano- y con algunos puntos de contacto con un socialismo genérico. Por último, el reformismo intentó expresar un programa generacional, una propuesta en alguna medida filosófica y antropológica -que tuvo entre sus principales inspiradores a José Ingenieros- que resaltaba el rol de la juventud ilustrada para la transformación de una sociedad sumida en la decadencia, la corrupción y el estancamiento. Sobre estas tres líneas maestras se montaría la tradición reformista, filón a partir de la cual se articularían diversas identidades que se reconocerían en ella.

Definiremos la tradición política siguiendo a Aboy Carlés (2015, p. 4) considerando que "supone un tipo especial de intervención intelectual que aísla y filia determinadas recurrencias tópicas sobre un conjunto de prácticas sociales empíricas y teóricas". En tal sentido, las tradiciones son el resultado de operaciones selectivas que establecen cierta filiación con un pasado. En el mismo sentido, Raymond Williams (2000) señala que las tradiciones resultan de: "una versión intencionalmente selectiva de un pasado configurativo y de un presente preconfigurado, que resulta entonces poderosamente operativo dentro del proceso de definición e identificación cultural y social" (p. 137). Las tradiciones son, de esta manera, elementos decisivos en la configuración y delimitación de las identidades políticas, más aún cuando permiten una multiplicidad de lecturas, incluso contrapuestas.

En este artículo analizaremos la experiencia del MNR, organización estudiantil que sirvió de semillero de los que luego sería el Partido Socialista Popular (en adelante, PSP), en especial el modo en que esta agrupación adoptó el discurso reformista y lo articuló para dar forma a una identidad política relativamente estable y sostenida en el tiempo. Para ello, indagaremos, en primer lugar, los rasgos distintivos de esta organización en su proceso de constitución y consolidación, en la década del sesenta: sus orígenes, sus principales dirigentes y sus vectores ideológicos. Luego, en una segunda instancia, repasaremos la "tradición reformista" recuperada por el MNR y de qué modo sirvió de pivote para su articulación identitaria. En tal sentido, veremos cómo el reformismo se constituyó en una referencia nodal en su configuración y en su derrotero posterior, una marca distintiva, con cierto potencial político, en tiempos donde primaba la radicalización política y la revitalización del peronismo.

\section{MNR: del reformismo universitario a la política partidaria}

Como ocurrió en otros ámbitos (desde los partidos hasta las Fuerzas Armadas, pasando por la Iglesia), la uniformidad antiperonista que siguió al golpe de 1955 fue más bien efímera. Desaparecido el factor aglutinante del polo opositor, el revitalizado reformismo universitario comenzó a agrietarse. La gran casa del reformismo, que había aunado a una porción importante de los jóvenes universitarios, parecía no tener suficiente capacidad para contener una serie de identidades políticas heterogé- 
neas, que tendieron prontamente a radicalizarse $y$ fragmentarse.

Sin embargo, esa tendencia general produjo también un fenómeno de rearticulación de un discurso reformista de nuevo signo, menos inclusivo y con una identidad más definida. El potencial político del reformismo universitario, en contacto con las ideas de la izquierda radicalizada pero autónoma con respecto a sus versiones más dogmáticas, fraguó en una serie de organizaciones -algunas más duraderas que otras- que se reivindicaron dentro de esa tradición política y le dieron una nueva impronta.

De entre esas agrupaciones políticas, por su trayectoria y relevancia, se destaca el MNR. Surgida al calor del apogeo de la llamada "nueva izquierda" (Tortti, 2014), tanto peronista como no-peronista, estableció una relación de diálogo, no exenta de conflicto, con esas expresiones políticas emergentes. Estos "herederos de la reforma", como no dudaban en reconocerse, se montaron sobre la tradición reformista, dejada de lado por muchos otros por sus limitaciones para interpretar el zeitgeist revolucionario que afloraba en la década del sesenta, y le reconocieron cierta potencialidad política. $\mathrm{Su}$ vinculación con el socialismo se mantuvo, pero siempre en una clave sui generis, más bien heterodoxa en su interpretación y sincrética en cuanto a referencias teórico-políticas.

La agrupación universitaria MNR se conformó al calor del refulgir del reformismo universitario tras la caída del peronismo, en el marco de un proceso de modernización y de profundas transformaciones en las instituciones de educación superior e investigación científica en nuestro país (Sarlo, 2007). Sin lugar a dudas, el parteaguas para la militancia universitaria, e hito fundamental en el surgimien- to del MNR, fue el conflicto desatado por el proyecto de reforma del artículo 28 de la Ley de Educación, motorizado inicialmente por Atillio Dell'Oro Maini, que se proponía habilitar a las instituciones privadas a ofrecer titulaciones de nivel superior (Califa, 2009). Esa disputa, que fue conocida como "laica o libre", fracturó al movimiento estudiantil. Alcanzó su cénit durante 1958, año en que la medida fue finalmente aprobada bajo auspicio del gobierno de Arturo Frondizi, e implicó el quiebre de las relaciones entre el gobierno y muchos sectores que originariamente habían apoyado al candidato de la Unión Cívica Radical Intransigente (UCRI) (Terán, 1991). Frente a ello, la Federación Universitaria Argentina (en adelante, FUA), controlada aún por un reformismo no-partidario, designó una Comisión de Acción en pos de la derogación del mencionado artículo 28 , cuya conducción recayó en el dirigente santafesino Guillermo Estévez Boero (Ceballos, 1985, p. 22).

La ruptura del movimiento estudiantil con el gobierno de Frondizi precipitó una radicalización en el discurso de sus principales dirigentes. En el año 1959, fue elegido como presidente de la FUA el propio Estévez Boero, representante de la Federación Universitaria del Litoral, como cabeza de una coalición de fuerzas reformistas de izquierda. ${ }^{4}$ Las resoluciones del IV Congreso de la FUA expresaban

4. Carlos Ceballos, quien fuera presidente de la FUA entre 1961 y 1963, explica que las agrupaciones reformistas de izquierda se caracterizaban por su independencia de los partidos políticos existentes $y$, fundamentalmente, por su no alineamiento con el Partido Comunista. En tal sentido: "en sus definiciones programáticas en política internacional se definían en contra del imperialismo norteamericano y el expansionismo soviético, pero sin caer en el anticomunismo de otras tendencias" (Ceballos, 1985, p. 25). 
con claridad el viraje del movimiento estudiantil hacia posiciones decididamente opositoras al frondicismo, con una explícita retórica contestataria y un mensaje cargado de consignas antiimperialistas. ${ }^{5} \mathrm{~A}$ modo de conclusión, instaba a la realización de una reforma agraria, un extenso plan de nacionalizaciones, el levantamiento de todas las proscripciones políticas, la libertad de los presos políticos y, concluía: "Activa participación del estudiantado junto a los trabajadores y los sectores afectados de la política imperialista impuesta por el Fondo Monetario Internacional, como base de la lucha de nuestra liberación" (Ceballos, 1985, p. 32).

El ámbito de la FUA fue el espacio propicio para la articulación de estos sectores reformistas independientes, en una coyuntura en que la politización partidaria comenzaba a vulnerar las fronteras de la institución universitaria. De esta manera lo describe el dirigente tucumano Marcos Rosa:

Transcurría el año 1959, y, dirigentes de izquierda estudiosos de Marx, de Engels y de sus continuadores, que no éramos antiperonistas y no militábamos en el $\mathrm{PC}$, nos encontrábamos en los Congresos, o en los CNC [Congresos Nacionales de Centros] de la FUA. Allí coordinábamos reuniones y emitíamos posiciones políticas con que ya nos identificábamos como MNR; había compañeros de Tucumán, de Rosario, de Santa Fe, de Córdoba, y del Centro de Ciencias Económicas de la UBA, todo eso inorgánicamente (en Movimiento Nacional Reformista, 2011, p. 15).

5. El documento de la FUA centraba su crítica al imperialismo y el latifundio, al tiempo que descalificaba el proyecto de Frondizi de promover la que ellos llamaban la "seudo-industrialización".
Fue así que, en el año 1960, comenzaron los primeros intentos de concretar una fuerza orgánica de alcance nacional de corte reformista, como respuesta al desbande provocado por esa creciente partidización. Los principales promotores eran Guillermo Estévez Boero, los cordobeses Edgardo Galetti y Carlos Ceballos, y el tucumano Marcos Rosa. ${ }^{6}$ Ceballos no prosiguió participando en la nueva organización, mientras los restantes tres dirigentes formaron parte de la primera conducción del nuevo agrupamiento.

Bajo el liderazgo de Estévez Boero, y luego de un periplo compartido, el MNR se constituyó formalmente en Horco Molle, provincia de Tucumán, en el año 1963: "Con Rosario-Santa Fe, Córdoba y Tucumán se lanza orgánicamente el Movimiento Nacional Reformista" (Marcos Rosa en Movimiento Nacional Reformista, 2011, p. 16). ${ }^{7}$ En esa instancia colectiva se dieron a conocer también los primeros documentos oficiales del MNR, en especial "Trabajemos mejor en casa" que fijaba las pautas generales de funcionamiento de la organización, afines al llamado centralismo

6. Entrevista a Marcos Rosa realizada por Fernando Manuel Suárez, febrero de 2016.

7. Entre las principales agrupaciones que se incorporaron al MNR se destacaban la Agrupación Pueblo y Reforma Indoamericana (APRI) de la Facultad de Medicina de la UNL y la Agrupación Reformista de Ciencias Económicas (AReCE) de la Facultad de Ciencias Económicas de la Universidad Nacional del Tucumán. Ambos nucleamientos aportarían, sin temor de exagerar, gran parte de los más importantes cuadros dirigentes que la organización tendría tanto en la política universitaria como en su desarrollo posterior. Entre ellos se destacan Hermes Binner, Juan Carlos Zabalza, Ernesto Jaimovich, Héctor Cavallero, Antonio Bonfatti, Mónica Fein -del APRI-, Gustavo Galland, Ángel García y Rodolfo Súccar-del AReCE-. 
democrático. ${ }^{8}$ Desde el punto de vista ideológico, el MNR combinaba banderas típicas del reformismo universitario con algunos rudimentos del marxismo. En síntesis, tal como ha señalado Inés Bertero:

1) el rechazo al seguimiento mecánico de los modelos extranjeros, 2) la unidad indestructible entre la juventud universitaria y las mayorías nacionales, 3 ) su definición por las ideas del socialismo, y 4) su convicción en la necesidad de una organización adecuada para alcanzar estos objetivos (Dalla-Corte Caballero, Álvarez y Prósperi, 2011, p. 40).

Sobre esa base, el MNR consagró "una corriente de la izquierda nacional que funcionaba con independencia de los aparatos partidarios" (Bebán y Llopis, 2014, p. 87). ${ }^{9}$ Su propuesta

8.El centralismo democrático es un dispositivo de ordenamiento partidario basado en un funcionamiento rígidamente piramidal y celular, es decir diseccionado en núcleos militantes disociados entre sí horizontalmente $\mathrm{y}$ articulados exclusivamente por el vértice. Las células son diseñadas como instancias no autogobernadas concebidas fundamentalmente para la ejecución de acciones ordenadas desde la cumbre, si bien se considera que estos espacios sirven para la discusión política de las bases. Las definiciones tomadas desde de las células deben ser elevadas para ser puestas en consideración por la cúpula partidaria, pero a priori no tienen un carácter vinculante ni mucho menos resolutivo. Por el contrario, las decisiones elaboradas desde la conducción, bajo el fundamento de ser el resultado de la consideración del conjunto de las resoluciones de las diferentes células partidarias, tienen un carácter imperativo e inapelable y requieren la ejecución sin dilaciones de los miembros subalternos. Para un análisis pormenorizado del centralismo democrático y su puesta en práctica en el MNR remitimos a Suárez (2018).

9. En el mismo sentido se expresa Marcos Rosa (Bebán y Llopis, 2014, p. 85): "no teníamos una identificación partidaria, ni peronista, ni radical, porque al principio era como algo apolítico, un fenómeno de masas dentro de la universidad que luego se iba a desarrollar. No se exigía ser socialista para pertenecer al MNR que aún no era el brazo universitario de nadie y tampoco teníamos articulaba una serie de reclamos gremiales específicos del movimiento estudiantil -ingreso irrestricto, concursos docentes, turnos de exámenes, afiliación automática a los centros de estudiantes, y otras cuestiones de bienestar estudiantil ${ }^{10}$ - con posicionamientos específicos sobre la política nacional y lecturas globales sobre el devenir político latinoamericano y mundial.

La agrupación reformista adoptó, desde sus inicios, un funcionamiento celular y, en cierta medida, verticalista. Su lema, acuñado en 1966, era -y lo es hasta hoy en día-: Estudiar, Organizar y Difundir. Lejos de ser una mera consigna, operaba como un imperativo para la militancia del MNR. La formación política, así como las tareas específicas de coordinación y difusión, eran estrictamente supervisadas por los llamados "responsables" en estrictas reuniones semanales. Así lo resumía Estévez Boero en 1972:

El militante (...) deberá estudiar, organizar y difundir. ¿Qué deberá estudiar? Deberá estudiar el gran pensamiento socialista de Marx y Engels, ya que el Socialismo es una ciencia, por eso se estudia y no se intuye. (...) $\mathrm{Al}$ estudio de los clásicos del marxismo deberá combinársele el estudio de la realidad nacional. El estudio de la realidad nacional marginado del ideario marxis-

relaciones con el Partido Socialista, que estaba más lleno de gorilas que de otra cosa”.

10. Sobre este tema se explaya Miguel Godoy (Movimiento Nacional Reformista, 2011, p. 29) y detalla las actividades desarrolladas por el MNR que incluían eventos deportivos y culturales, la creación del comedor universitario, la distribución de materiales de estudio (apuntes, clases desgrabadas, etc.), y la creación de residencias para estudiantes del interior, entre otras muchas cuestiones. 
ta lleva simplemente a crear vanas salidas como el populismo y el desarrollismo. (...) Pero además, los compañeros (...) deben ORGANIZAR(se) en base a un mínimo de comunidad ideológica, teniendo tres objetivos centrales e indispensables (...): el trabajo colectivo, el estudio colectivo y la elaboración colectiva. (...) Por último los compañeros (...) deben dentro de nuestra trilogía de trabajo, DIFUNDIR en forma permanente nuestros objetivos. ${ }^{11}$

El MNR, como parte de un reformismo beligerante, intensificó su actividad y elevó su perfil combativo una vez consumado el golpe de estado de 1966 encabezado por Juan Carlos Onganía. En ese marco, se opuso de manera frontal al gobierno autoritario y, puntualmente, a su intervención en la política universitaria. ${ }^{12}$ En 1967, se expresaba con contundencia en un documento titulado "Reforma o contrarreforma" en el que objetaba las propuestas del gobierno militar en esa materia como medidas, a su entender, orientadas a

reprimir al estudiantado y sus organizaciones, concordando con la obra de gobierno, que se ha dado a la tarea de reprimir a toda organización popular. En primer lugar, se reprime a quienes pretenden ingresar a la

11. "La huella de Palacios I", PSP, 1972, Partido Socialista, Buenos Aires.

12. Respecto del gobierno dictatorial afirmaba: "Los representantes de los monopolios extranjeros y la oligarquía nativa se apoderan de los resortes administrativos de la Nación. (...) Núcleos sin respaldo popular, encaramados en la función gubernamental y encubiertos por un pseudo-nacionalismo oligárquico, pretenden sin pausa llevar a la realidad sus trasnochados devaneos. Desde las altas esferas de la banca y desde los más oscuros rincones surge la escoria que velozmente se precipita a ocupar los puestos de gobierno.”. Reforma o contrarreforma, MNR, 1967, Fundación Estévez Boero, Rosario.
Universidad y, en segundo lugar, a quienes han logrado penetrar en ella. ${ }^{13}$

Desde esa oposición, al régimen militar, el MNR convergió con sectores combativos del movimiento obrero, en especial la CGT de los Argentinos. ${ }^{14}$ En ese marco, de creciente virulencia política, sus jóvenes dirigentes participaron activamente en los procesos de resistencia contra el gobierno militar, donde confluyeron de manera inédita los sindicatos con la militancia estudiantil, cuyo hito más significativo fue el Cordobazo. ${ }^{15}$ Además de su participación en Córdoba, también en Tucumán y Rosario el MNR tuvo un desempeño activo en estos movimientos de protesta. Allí confluyó tanto con otras expresiones reformistas como con las incipientes formaciones de la "nueva izquierda", con las que ya comenzaba a manifestar sus diferencias. ${ }^{16}$

13. "Reforma o contrarreforma”, MNR, 1967, Fundación Estévez Boero, Rosario.

14. Entrevista a Héctor Cavallero realizada por Fernando Manuel Suárez, octubre de 2015. También el testimonio de Raúl Garo en Dalla-Corte Caballero, Álvarez y Prósperi (2011, p. 136).

15. Para un muy pormenorizado análisis de los ciclos de movilización estudiantil durante los gobiernos de la Revolución Argentina remitimos al muy exhaustivo trabajo de Millán (2013).

16. En tal sentido, en un documento titulado "El MNR y la lucha del pueblo argentino contra la dictadura y el imperialismo" (1969) manifestaba sus diferencias con ciertos sectores radicalizados a los que homologaba con el gobierno militar por estar "hermanados en su aislamiento y desprecio por las mayorías nacionales". En tal sentido afirmaba: "En esta lucha, el pueblo, las grandes mayorías nacionales, los trabajadores, los estudiantes, han obligado a sus dirigentes a unificarse. Todos aquéllos que pretendían mantener organizaciones vanguardistas, que jugaran como reflectores de la luna, fueron derrotados por las masas, tuvieron que poner sus planes en sus bolsillos y participar en las movilizaciones del pueblo, como las marchas del silencio y los paros generales. Desde los núcleos más sectarios hasta las entidades que 
En 1969, la conducción de la organización expresaba:

E1 Movimiento Nacional Reformista estuvo en la defensa de la Autonomía Universitaria y en la activa resistencia a la Intervención Universitaria (...). Hemos estado con portuarios y ferroviarios, hemos estado en la defensa de los gremios intervenidos, hemos estado con la lucha de los trabajadores de Tucumán y del Norte Santafesino, hemos estado en la condena de la Ley de Farmacias, en contra de la enajenación de los servicios asistenciales. Hemos defendido servicios sociales de los trabajadores y de los estudiantes; hemos estado, y estamos, en la defensa de los derechos y libertades de los ciudadanos argentinos; hemos estado, y estamos, en la defensa del patrimonio nacional, económico y cultural de la Nación. (...) Estas luchas, a pesar de su aparente aislamiento, reconocen en su esencia una unidad: El estar todas ellas motivadas por la agresión y la represión de la Dictadura Militar en beneficio exclusivo de los monopolios extranjeros. ${ }^{17}$

Tras esos acontecimientos y fruto de la apertura política que se propició tras la salida de Onganía del gobierno, el MNR redobló sus esfuerzos militantes. En ese período, en especial en Rosario, había ampliado su participación a otros terrenos sobre la base de su primera camada de graduados que empezó a desarrollar tanto un ingente trabajo barrial

más han retaceado su participación en la lucha contra la Dictadura se vieron obligados, ante el clamor popular a adherirse a las movilizaciones decretadas por las mayorías nacionales". El MNR y la lucha del pueblo argentino contra la dictadura y el imperialismo, 1969, Fundación Estévez Boero, Rosario.

17. "E1 MNR y la lucha del pueblo argentino contra la dictadura y el imperialismo", 1969, Fundación Estévez Boero, Rosario. como cierta inserción en el mundo gremial. ${ }^{18}$ Esa expansión marcaba también los límites de una estructura orientada específicamente a la política universitaria. A raíz de ello, comenzó a discutirse la posibilidad de conformar un "movimiento de opinión”. ${ }^{19}$ De esta forma lo relata Juan Carlos Zabalza:

Esta fuerza, que se aglutina a través de los postulados de la reforma universitaria y la reivindicación de una universidad pública, laica y sin ingreso, también empieza a mezclarse y a preocuparse por lo que pasaba en el país, donde las fuerzas de izquierda en ese momento estaban capitalizadas por el comunismo y por el trotskismo. Por otro lado, la existencia de un bloque socialista con gente respetable, pero de escasa representatividad, y muy cargada por la lucha antiperonista. $Y$ va naciendo y se va consolidando en nosotros un objetivo, primero, de generar una fuerza política -porque ahí ya muchos éramos graduados universitarios- $y$ se da también una necesidad de participa-

18. En entrevista a Héctor Cavallero realizada por Fernando Suarez, noviembre de 2015 y en Bebán y Llopis (2014, pp. 90-91) se menciona que durante ese período se desarrollaron agrupaciones en distintas ramas, entre ellas se destaca: construcción, ferroviarios -todavía como MNR-, de la carne, del tractor, sanidad, docente, comercio, municipales y bancarios - con el MAPA-. En el mismo sentido se expresa Víctor Hugo Vallejos para el caso cordobés señala que se desarrollaron las ramas del seguro, municipales, luz y fuerza, docente, bancarios, obras sanitarias, comercio y judiciales. Entrevista a Víctor Hugo Vallejos realizada por Fernando Manuel Suárez, septiembre de 2015. También Marcos Rosa narra también los contactos fluidos del MNR-MAPA con la Federación Obrera de Trabajadores de Ingenios Azucareros (FOTIA) de Tucumán. Entrevista a Marcos Rosa.

19. Héctor Cavallero comenta: "Entonces yo fui a hablar con él [Estévez Boero] y le dije: "tenemos que impulsar ahora una corriente de opinión". Porque no nos daba el cuero para hacer un partido político. Creamos el MAPA". Entrevista a Héctor Cavallero, noviembre de 2015. 
ción de otros grupos sociales, trabajadores principalmente, y por eso nace el MAPA aquí en Rosario, siempre con algún correlato en Córdoba y Tucumán. ${ }^{20}$

En 1970, en este afán de participación política, el MNR había respaldado a través de un comunicado la convocatoria de "La Hora del Pueblo". ${ }^{21}$ En tal sentido, el Movimiento de Acción Popular Argentino (en adelante, MAPA) fue el resultado de la expansión de la agrupación universitaria y la primera manifestación de interés por parte de este grupo de reformistas no-alineados de participar en la política partidaria. Fue en ese marco que comenzaron las tratativas y los intentos de confluir en una organización mayor. De entre las opciones posibles, la conducción del MAPA se decantó por el Partido Socialista Argentino con el que tenía mayor grado de acuerdo. Lo cierto es que algunos de sus más importantes miembros habían tenido algunos acercamientos con alguna expresión del socialismo argentino en años previos, aunque todas estas experiencias no habían llegado a buen puerto. ${ }^{22}$ No obstante ello, en abril de 1972, se firmó el acuerdo que articulaba al joven MAPA con el

20. Entrevista a Juan Carlos Zabalza realizada por Fernando Manuel Suárez, noviembre de 2015.

21. Véase: Acerca de la declaración efectuada por la mayoría de los partidos políticos, 1970, Partido Socialista, Buenos Aires.

22. La más conocida de ellas fue la participación de un joven Guillermo Estévez Boero en la agrupación Acción Socialista liderada por Dardo Cúneo y luego transformada efímeramente en el Partido de los Trabajadores, ver Herrera (2013). Otra, menos pública, fue la iniciativa de algunos dirigentes del APRI Cavallero, Zabalza, Binner, entre los más destacadosde afiliarse al Partido Socialista Argentino en 1965, experiencia que terminaría con la expulsión de casi todos ellos por "peronistas y comunistas". Entrevista a Juan Carlos Zabalza y Entrevista a Héctor Cavallero, noviembre de 2015 .
PSA, luego de un largo periplo de diálogos que incluía a los dirigentes del Grupo Evolución y Militancia Popular, los dos socios restantes en la empresa del flamante PSP. En ese nuevo partido el grupo dirigente proveniente del MNR jugaría un importante rol que, de un modo u otro, continúa hasta nuestros días. ${ }^{23}$

\section{La tradición reformista: avatares de un ideario a lo largo del tiempo}

El reformismo en la Argentina puede ser interpretado, grosso modo, en dos sentidos diferentes. En primer lugar, refiere a una tendencia política proclive al gradualismo y opuesta a cualquier alternativa de acción insurreccional. En segundo término, retrotrae a la tradición reformista universitaria argentina, un movimiento que ganó visibilidad a principios del siglo XX y que se convirtió, a través de diversas y heterogéneas organizaciones políticas, en una corriente central en el devenir de la política universitaria hasta nuestros días. Aún con vasos comunicantes entre sí, estas dos nociones diferentes de reformismo han sido una marca distintiva del MNR.

En su sentido más amplio, en la tradición socialista remite a una perspectiva política que promovía una estrategia acumulativa, de transformaciones parciales, en el camino a la configuración de una sociedad igualitaria. Los reformistas advertían con recelo las consecuencias

23.La enorme mayoría de los principales dirigentes del actual Partido Socialista (resultante de la fusión entre el PSP y el Partido Socialista Democrático en el año 2002) se formaron como militantes en las filas del MNR, entre ellos podemos destacar el caso de los últimos tres gobernadores de la provincia de Santa Fe: Hermes Binner, Antonio Bonfatti y Miguel Lifschitz. 
que la opción insurreccional, encarnada por la experiencia soviética, traía aparejadas, llamando la atención sobre su carácter autoritario y militarista. En término concretos, el reformismo representaba un programa político que, sin desechar los objetivos maximalistas, optaba por participar de las instancias democráticas que el sistema vigente otorgaba e impulsar, desde allí, diferentes medidas que apuntaran a mejorar la vida de la clase trabajadora.

La segunda forma de concebir el reformismo, $y$ en este caso de mayor importancia, tiene que ver con la tradición universitaria argentina cuyo filón se encuentra plasmado en el muy conocido Manifiesto Liminar. ${ }^{24} \mathrm{La}$ inscripción del MNR en esta tradición no presenta ninguna sorpresa, la propia nominación de la organización define esta pertenencia. ${ }^{25} \mathrm{La}$ tradición reformista aunaba una serie de principios doctrinarios, referentes intelectuales y propuestas programáticas cuya significación serían centrales en la configuración identitaria de este espacio político, tanto en su versión específicamente universitaria como en su deriva posterior como partido político. El "mito reformista" tuvo una enorme vigencia política y se concibió desde un principio como una referencia allende las fronteras de la institución que le había dado origen (Portantiero, 1977; Romero, 1998).

Como acontecimiento político, la Reforma Universitaria significó un parteaguas dentro de una institución signada por el conservaduris-

\section{Ver Roca (2006 [1918]).}

25. "Esta fuerza, que se aglutina a través de los postulados de la reforma universitaria y la reivindicación de una universidad pública, laica y sin ingreso" describe Juan Carlos Zabalza al núcleo militante que transitó desde el MNR al PSP. Entrevista a Juan Carlos Zabalza. mo y la venalidad. ${ }^{26}$ La demanda por la participación estudiantil en el cogobierno de la universidad era una de las banderas principales de ese movimiento, y estaba asociada una serie de reclamos que apuntaban a la democratización y transparencia de una institución caracterizada como "el refugio secular de los mediocres, la renta de los ignorantes, la hospitalización segura de los inválidos y-lo que es peor aún- el lugar en donde las formas de tiranizar hallaron la cátedra que las dictara" (Roca, 2006 [1918], p. 27). Sin embargo, la agenda expuesta por los reformistas pretendía ir más allá de esos reclamos puntuales, consideraban que la transformación universitaria era el primer escalón en una serie de reformas sociales más profundas que debían llevarse adelante en "estas sociedades decadentes" (Roca, 2006 [1918], p. 27): "La reforma representaba, aun sin que lo supieran siempre con claridad sus ideólogos y sus dirigentes, bastante más que un mero episodio estudiantil." (Portantiero, 1977, p. 13).

De ese modo, el reformismo universitario se concibió como una vanguardia político-intelectual -una "nueva generación"- con profunda vocación transformadora, un movimiento que se desplegaba a escala continental con una explícita prédica antiimperialista. Articuló una red intelectual transfronteriza que promovió el desarrollo de un pensamiento ilustrado, progresista $\mathrm{y}$, por supuesto, reformista, con la participación de figuras de gran renombre como José Ingenieros o José Vasconcelos, entre muchos otros (Pita, 2004). Asimismo, inspiró proyectos políticos de diversa envergadura y disímil éxito en todo el continente. La tradición reformista formó parte de la identidad política del MNR y, luego del PSP, a través de

26. Para una reconstrucción minuciosa del proceso histórico en la Argentina remitimos a Bruera (2010). 
los tres carriles señalados: como un programa de acción política universitario, como una tradición intelectual, y como un proyecto político en sentido estricto.

Durante largo tiempo, quizá hasta muy avanzada la década del sesenta, el reformismo fue la corriente más contestataria y proactiva de la militancia política universitaria. Anudaba dentro de sí diferentes identidades político-ideológicas articuladas mediante el lenguaje común de la reforma, esta persistencia se explicaba en algún modo por los propios condicionantes -frenos y retrocesos- que sufrió el proyecto reformista durante la primera mitad del siglo XX (Biagini, 2000). La agenda reformista pervivió en la medida que se vio amenazada por sus adversarios, es decir aquellos que atentaban contra su autonomía o violaban el cogobierno. ${ }^{27}$

Los años del peronismo profundizaron las tensiones del programa reformista frente a un gobierno al que veían con desconfianza, porque si bien en ese período se dieron avances significativos en la ampliación del acceso a los estudios superiores esto se hizo en desmedro de otro de los pilares reformistas: la autonomía universitaria. Ese proceso generó un efecto doble: por un lado, el reformismo se replegó sobre sí mismo y menguó su incidencia por fuera de los claustros y, por el otro, esto produjo cier-

27. "Vulnerables a los albures del Estado, las universidades argentinas engendraron una suerte de comunidad, originada en la alianza entre estudiantes y profesores -o intelectuales progresistas- en 1918 y que se perfila como cuerpo universitario en 1943. Este cuerpo poseía un territorio, una articulación institucional y una doctrina. [...] En efecto, las cisiones en el interior de la Universidad estuvieron organizadas exclusivamente en función de la Reforma, y con ella, de esa gran divisoria de aguas que fue el laicismo" señala Silvia Sigal (1991, pp. 69-70). ta homogeneización articulada por un discurso antiperonista. No casualmente la universidad se convirtió en uno de los escenarios más dinámicos y activos tras el golpe de estado que derrocó al peronismo, y allí la militancia estudiantil reformista tendría un papel destacado. ${ }^{28}$

Este consenso reformista alcanzó su cénit en el conflicto "laica o libre", justamente durante la presidencia de Guillermo Estévez Boero -indiscutido líder y principal referente del MNRen la FUA (Ceballos, 1985). La década del sesenta significó, en la opinión de Sigal, el fin del consenso reformista y la evidencia de que ya no era eficaz para contener las identidades político-ideológicas emergentes, no obstante ello ese mismo espacio identitario habilitó la emergencia de una multiplicidad de expresiones políticas que se reconocían en dicha raíz. ${ }^{29}$ Al mismo tiempo, como proceso simultáneo y con algunos puntos de contactos con este, se produjo una revitalización del peronismo, es decir una inédita peronización de los claustros universitarios (Barletta, 2000). Del panorama previo, dominado por reformistas y católicos (humanistas e intergralistas), pasamos a un escenario durante la década del sesenta que mostraba una mayor fragmentación y la constitución de agrupaciones universitarias vinculadas a referencias político-partidarias más nítidas, cuya principal novedad era la aparición de agrupaciones de izquierda y peronistas (Friedemann, 2017).

28. Véase, Pis Diez (2012).

29. En el mismo sentido se expresa Califa (2014): “Los militantes reformistas se irían dividiendo en un ala asumida de "izquierda", donde el comunismo empezaba a destacarse, y otra acusada por aquélla de "derecha". Las cuestiones que separaban a los jóvenes reformistas tenían su punto de inflexión en los avatares de la política nacional" (p. 99). 
En esa deriva, el MNR mantuvo su adscripción a los símbolos y tópicos típicamente reformistas en un contexto en que este, aún hegemónico, se vio atravesado por un inédito fraccionamiento en clave partidaria que complejizó las relaciones políticas dentro de la universidad y fuera de ella. En esa fragmentación, tuvo una estrecha relación con los sectores políticos que conformarían la Franja Morada, con los que compartía una raíz ideológica común y una serie de coincidencias programáticas, como por ejemplo su posición adversa con respecto a la lucha armada. No obstante ello, el MNR representaba un reformismo peculiar, afecto al entendimiento con el sindicalismo combativo, muy activo en los procesos de lucha contra los gobiernos autoritarios y con un discurso nítidamente de izquierda. ${ }^{30}$ Esto se refleja, por ejemplo, en un documento de la FUA -conducida por la coalición MNR- Franja Morada-de 1973:

Rendimos homenaje con esto a quienes, en 1918, plantearon una cultura popular, la unidad obrero-estudiantil y la lucha contra el imperialismo. Esta es la convocatoria que realiza la FUA el 15 de junio de 1973 a todos los estudiantes universitarios argentinos para aportar, con nuestro estudio, con

30. Así lo explica Mariano Millán (2013): “Afirmamos que la radicalidad de la militancia universitaria se debió fundamentalmente a la reconfiguración del reformismo bajo un gobierno represivo, entrando los estudiantes en relación con los procesos de movilización obrera y la crisis posconciliar en el contexto de los conflictivos años ' 60 .

[...] En el marco de una situación política caracterizada por la abolición del cogobierno universitario, la ilegalización de sus instituciones y las consiguientes mutaciones en las formas organizativas, gremiales y políticas, los reformistas conservaron y potenciaron su capacidad de movilización" (pp. 10-23). Esta afirmación, si bien no se refiere estrictamente al caso estudiado en el presente artículo, sirve de argumento para reflexionar con respecto al devenir de dicha agrupación en ese contexto histórico específico.

158 nuestra lucha y nuestro trabajo, junto a las mayorías nacionales, a transitar el sendero de la liberación nacional. ${ }^{31}$

El segundo punto a analizar tiene que ver con la herencia específicamente intelectual del ideario reformista, tanto en sus preceptos como en sus referentes. Los jóvenes protagonistas de la Reforma Universitaria tuvieron una suerte dispar en sus trayectorias posteriores y muchos de ellos, como parte de una experiencia colectiva significativa, quedaron en el olvido o nunca lograron trascender el anonimato. ${ }^{32}$ Por el contrario, los referentes intelectuales más célebres de este movimiento fueron los llamados "maestros del reformismo": figuras intelectuales consagradas y de cierto renombre que oficiaron de guía tutelar para los jóvenes levantiscos. Entre ellos se destacaba por sobre los demás José Ingenieros, un médico notable, original pensador y escritor polifacético, que se convirtió en un ícono indiscutido para los reformistas. ${ }^{33} \mathrm{El}$ rol de estos maestros estaba en ofrecer una tutela ideológica, expandir los límites políticos y ampliar la resonancia de las acciones llevadas adelante por los más jóvenes. En tal sentido, estas figuras fueron claves para proyectar el ideario reformista extramuros y lograr estos valores tuvieran un sentido más allá de la política estudiantil: "Será precisamente

31. Documento de la FUA "Trabajo voluntario de los estudiantes universitarios por la liberación nacional”, 15 de junio de 1973, Fundación Estévez Boero, Rosario.

32. Esta disparidad de trayectorias se puede corroborar fácilmente en las sucesivas ediciones del clásico libro de Horacio Sanguinetti y Alberto Ciria (2006) titulado precisamente: La Reforma Universitaria.

33. La figura de José Ingenieros ha generado un notable interés en la historiografía y, por tanto, es muchísima la bibliografía que se ha dedicado a retratar su figura, a analizar su obra o a reconstruir su trayectoria. Centrado en su actividad específicamente asociada al reformismo véase Pita (2009). 
su expansión americana la que consolidará a la Reforma como un movimiento político-social a la vez que complejizará sus postulados iniciales.” (Cattáneo y Rodríguez, 2000, p. 50).

El espacio concebido para extender el influjo reformista fue "La Unión Latino Americana" (ULA). ${ }^{34}$ Esta organización intelectual continental profundizó y radicalizó discursivamente aquellos elementos que se anunciaban tímidamente en el ideario reformista, fundamentalmente el antiimperialismo (Kozel, 2015). Las figuras intelectuales más representativas de esta experiencia fueron el ya mencionado José Ingenieros y Alfredo Palacios, y, en un cercano segundo plano, Manuel Ugarte. Curiosamente estos tres personajes no solamente oficiaban como referentes de los jóvenes reformistas e intelectuales del antiimperialismo (Cormick, 2009), sino que, de manera muy disímil entre sí, todos formaron parte -muchas veces como disidentes- del Partido Socialista. ${ }^{35}$ Esta fi-

34. La Unión Latino Americana (ULA) se constituyó formalmente en el año 1925 y fue presidida desde sus inicios por Alfredo Palacios, secundado, en el rol de secretario general, por otro socialista: Carlos Sánchez Viamonte (ver Pita, 2004). Desde sus orígenes la ULA se propuso coordinar la acción de los intelectuales del continente y promover la confluencia de las naciones latinoamericanas en un espacio confederado en clave antiimperialista. Los lineamientos generales de la ULA, así como sus propuestas programáticas, se pueden ver en Palacios (1961).

35. La participación del José Ingenieros en el Partido Socialista resulta un dato subsidiario en su biografía política e intelectual cuyo hito más significativo fue la edición del periódico La Montaña junto a Leopoldo Lugones. A Manuel Ugarte, por su parte, también lo precedía una fama intelectual significativa, sin embargo su participación en el PS ha ganado relevancia sobre todo a partir de la recuperación postrera que hicieran algunos sectores de la izquierda nacional. Ugarte es considerado un pionero en la defensa de un socialismo antiimperialista, 'anti-yanqui', y con cierta sensibilidad nacional. Finalmente, Alfredo Palacios es probablemente liación entre reformismo, antiimperialismo y socialismo signó la trayectoria de muchos dirigentes reformistas en la primera mitad del siglo XX y fue clave para la articulación identitaria que hicieron los socialistas populares posteriormente. ${ }^{36}$ Ingenieros, Ugarte y Palacios fueron referencias claves en la formación de la militancia del MNR y del PSP (Bebán y Llopis, 2014). ${ }^{37}$

Esto abre paso al tercer y último punto de la tradición reformista que nos interesa analizar: las experiencias políticas concretas. Si bien ellas no están completamente disociadas de la militancia universitaria ni de los enclaves intelectuales: el imperativo de concebir un proyecto político reformista con proyección política nacional fue uno de los puntos más álgidos para esta tradición, al menos en la Argentina (Cattáneo y Rodríguez, 2000). Los reformistas encontraron en la Argentina muchas dificultades para traducir la experiencia de formación política universitaria en un proyecto político

la figura más asociada al Partido Socialista -a pesar de haber sido expulsado en dos oportunidades-, por lo que muchas veces ha quedado subsumido a un segundo plano su rol como articulador y referente del campo reformista latinoamericano articulado en torno a la ULA.

36. Muchos dirigentes estudiantiles ligados a la reforma del dieciocho tuvieron alguna incursión en el Partido Socialista, entre ellos se destacan el emblemático Deodoro Roca, Julio V. González, Arturo Orgaz, Alejandro Korn, entre muchos otros. Sobre este vínculo, véase Graciano (2008).

37. Otro referente fundamental para los militantes del MNR fue Gabriel del Mazo, probablemente el más prolífico autor en lo que respecta al análisis del reformismo, siendo él a la vez testigo y protagonista. Sin embargo, su participación en el gobierno de Arturo Frondizi, muy denostado por el reformismo, produjo su exclusión del panteón oficial dentro del MNR. Este episodio ilustra, quizá mejor que otros, el modo en que la tradición se moldea de modo selectivo en base a criterios contemporáneos y no permanece incólume. 
partidario condicionado por la convulsionada situación política en el período de entreguerras. En ese marco, el tímido y tardío intento por conformar un Partido Nacional Reformista, motorizado fundamentalmente por Julio V. González, se dio de trastes con una realidad política poco permeable a esta iniciativa. ${ }^{38}$

Sin embargo, el reformismo sí logró construir organizaciones político-partidarias de gravitación en otras latitudes. La más destacada de ellas fue la Alianza Popular Revolucionaria Americana, más conocida por su acrónimo APRA, en el Perú que "sería la expresión más perdurable de la transformación de los ideales de la Reforma Universitaria en un partido político" (Sessa, 2013, p. 32) ${ }^{39}$ El APRA, fundado en 1924, se convirtió en la experiencia política más relevante heredera de la Reforma Universitaria, la revolución mexicana y la ULA, y su principal líder, Víctor Raúl Haya de la Torre, se convirtió en una referencia política e intelectual de gran gravitación. Su prédica antiimperialista y latinoamericanista, su socialismo no dogmático, y su sensibilidad popular e indigenista se convirtieron en marcas distintivas de esta fuerza y en una referencia a escala continental, con particular influjo en la Argen-

38. En 1945, en el prólogo a su libro, Julio V. González (1945: p. 11) expresaba: "Mas no olvide el estudiante reformista que la conquista de la universidad, es sólo un medio para lograr el supremo fin de transformar con sus propias manos el país, revitalizándolo mediante la implantación de una democracia social, donde la riqueza no sea el privilegio de unos pocos, el bienestar un lujo y el trabajo una maldición”. Véase: Ciria y Sanguinetti (2006).

39. La Alianza Popular Revolucionaria Americana fue concebido como un espacio de articulación continental, en paralelo a la propia ULA, posteriormente Haya de la Torre fundaría el Partido Aprista Peruano (PAP) en el Perú. Véase, Manrique (2009) y Nieto Montesinos (2000). tina (Sessa, 2013) ${ }^{40} \mathrm{El}$ aprismo contribuyó a delinear los trazos gruesos teórico-políticos del proyecto reformista, pero también estableció algunos puntos programáticos que fueron retomados de manera muy clara por el MNR, primero, y por el PSP, después. ${ }^{41} \mathrm{El}$ propio Estévez Boero caracterizaba al APRA como “(...) la creación política más genuina surgida del movimiento juvenil latinoamericano" (Estévez Boero, 1988, p. 213).

De los múltiples puentes que se pueden tender entre el reformismo universitario como movimiento político e intelectual amplio y la experiencia del MNR, MAPA y PSP se puede derivar una pregunta: ¿fue acaso el PSP liderado por Estévez Boero la concreción tardía del proyecto del partido reformista trunco en la década del veinte? La evidencia nos permite establecer lazos evidentes entre la tradición reformista y el proyecto político del socialismo popular, pero también es tangible la porosidad $\mathrm{y}$ muchas intersecciones que anudaron al reformismo con el socialismo tanto en la Argentina como en América Latina. Esa conjunción entre socialismo y reformismo, anudados al nacionalismo mediante de la tesis antiimperialista, fueron los rasgos constitutivos del MNR en su primera década de vida.

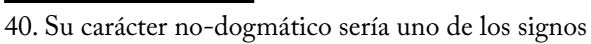
distintivos del APRA, pero también por ello ha sido interpretado críticamente como un partido volátil e inconsistente.

41. Los cinco puntos fundamentales del programa aprista eran: "1. Acción contra el imperialismo yanqui. 2. Unidad política de América Latina. 3. Nacionalización de tierras e industria. 4. Internacionalización del Canal de Panamá. 5. Solidaridad con todos los pueblos y clases oprimidas del mundo." (Manrique, 2009, p. 31). 


\section{Conclusiones}

A lo largo de este artículo nos interesó indagar la Reforma Universitaria a través de una lente diferente. No nos enfocamos estrictamente en los sucesos del 18 -ni en sus principales referentes, ni en su impacto en América Latina-, sino que abordamos el reformismo como una tradición política, es decir como un fenómeno más etéreo pero de más largo aliento. La larga sombra del reformismo, cuyo predicamento a escala continental fue realmente excepcional (quizá solo equivalente al de la revolución cubana), ha sido leída principalmente a partir de sus consecuencias más inmediatas -y por ello más evidentes en su ligazón- y en sus efectos durables en las instituciones universitarias, especialmente las argentinas, pero no así en su potencial específicamente político e identitario $^{42}$.

La década del sesenta fue particularmente convulsa para la política argentina y aún más para la política universitaria. La proliferación de ideas de izquierda renovadas, resultado de un heterogéneo fenómeno de revisión de la experiencia peronista, una relectura de las ideas marxistas, y una revalorización de la vía revolucionaria al calor de las experiencias exitosas en países periféricos (Tortti, 2014), produjeron una aparente crisis del reformismo y su marginación frente a la "radicalización" y la "peronización" de los claustros. Sin embargo, lo que entró en crisis fue el reformismo ecuménico engendrado durante los años peronistas, un

42.Algunos trabajos de más largo aliento, a nuestro entender, carecen de un aparato crítico para problematizar el fenómeno reformista, asumiendo un continuismo prácticamente sin matices a lo largo del tiempo. Nosotros consideramos que se existe tal ligazón a lo largo del tiempo, pero no puede pensarse en un reformismo idéntico a sí mismo. reformismo inclusivo pero sumamente laxo en definiciones ideológicas y renuente a filiaciones partidarias demasiado explícitas.

Frente a esa crisis, la bandera reformista fue asumida por una serie de actores que por diferentes motivos no se montaron en la ola de la radicalización de la "nueva izquierda" -si bien compartían algunos tópicos e inquietudes con esas organizaciones- y quedaron, a su manera, huérfanos de una referencia política. Consideramos que, a medida que el reformismo fue perdiendo su carácter consular, recuperó su potencial político, como una tradición pasible de articular identidades políticas quizá más restringidas pero también más homogéneas y con fronteras más nítidas. De esas organizaciones, nos abocamos a analizar la experiencia del MNR, fundado en 1960 y que persiste hasta nuestros días bajo el mismo nombre.

E1 MNR adoptó de manera integral el programa político e intelectual del reformismo universitario y abrazó esa tradición de manera explícita: su propia nominación es el signo más irrefutable de ese compromiso. Si bien su configuración identitaria fue el resultante de la articulación con otras tradiciones políticas, como el socialismo (marxista y no-marxista) y cierto nacionalismo -nacionalismo popular, en sentido estricto- (Suárez, 2018), la primacía del primero parece ser un rasgo distintivo de esta organización, tanto en su versión universitaria como en su deriva político-partidaria. En tal sentido, la tradición reformista, con sus rasgos originarios de afinidad con el socialismo y una encendida retórica antiimperialista, mostró un potencial articulatorio significativo, esto permitió al MNR vincularse a partir de esa inscripción principal y, de ese modo, surcar las convulsas aguas de la década del sesenta, vinculándose con las ideas y las organizaciones 
de la "nueva izquierda" pero sin sucumbir del todo a las tentaciones que ofrecía el contexto de radicalización política.

La proyección del ideario reformista del MNR en su conversión en movimiento de opinión, primero, y en partido político, después, es algo que todavía requiere ser comprobado. Sin embargo, tenemos indicios, algunos de los cuales han sido presentados aquí, de que efectivamente el reformismo como tradición política continuó teniendo un rol preponderante en la articulación identitaria del MAPA y del PSP. Asimismo el MNR continuó siendo, hasta hoy día, la principal fuente de reclutamiento militante del partido: la amplia mayoría de los dirigentes del PSP -hoy Partido Socialista (PS), a secas- participaron en algún momento de su organización universitaria. Quizá el PSP fue, en definitiva, el Partido Reformista posible, el realmente existente. La puesta en acto de una tradición reformista que, tras atravesar, nunca indemne, los sinuosos e inciertos senderos de la historia, dio forma a una organización política con su nombre.

$$
\propto \tilde{e} \propto
$$

Recibido: 05-09-2018

Aceptado: 26-04-2019

Publicado: 04-06-2019 


\section{Referencias Bibliográficas}

Aboy Carlés, G. (2015). Tensiones entre populismo y democracia liberal. Ponencia presentada en VIII Congreso Latinoamericano de Ciencia Política, Lima, Perú.

Barletta, A. (marzo de 2000). Universidad y politica. La peronización de los universitarios. Ponencia presentada en XXII International Congress of the Latin American Studies Association, Miami, Estados Unidos.

Bebán, O. y Llopis, E. (2014). Socialismo. De la teoría a la práctica: conversaciones con Héctor "El Tigre" Cavallero. Rosario: De Aquí a la Vuelta.

Biagini, H. (2000). La reforma universitaria. Antecedentes y consecuentes. Buenos Aires: Leviatán.

Bruera, L. (2010). La Reforma Universitaria y el surgimiento de una nueva generación intelectual argentina con proyección latinoamericana (Tesis doctoral inédita). Universidad Nacional de Rosario, Rosario, Argentina.

Bustelo, N. (2018). Todo lo que necesitás saber sobre la reforma universitaria. Buenos Aires: Paidós.

Califa, J. S. (2009). El movimiento estudiantil reformista frente al primer episodio de la "laica o libre" (mayo de 1956). Sociohistórica, (26), 51-79. Recuperado de http://sedici.unlp.edu.ar/handle/10915/13756

Califa, J. S. (2014). La socialización política estudiantil en la Argentina de los sesenta. Perfiles educativos, 36(146), 98-113. Recuperado de https:/www.sciencedirect.com/science/article/pii/ S0185269814701308?via\%3Dihub

Cattáneo, L. y Rodríguez, F. D. (2000). Ariel exasperado: avatares de la Reforma Universitaria en la década del veinte. Prismas. Revista de historia intelectual, (4), 47-57. Recuperado de http://www.unq.edu.ar/ advf/documentos/567303e159a00.pdf

Ceballos, C. (1985). Los estudiantes universitarios y la politica (1955-1970). Buenos Aires: CEAL.

Ciria, A. y Sanguinetti, H. (2006). La Reforma Universitaria (1918-2006). Santa Fe: Universidad Nacional del Litoral.

Cormick, S. (2009). Figuras de izquierda y pensamiento latinoamericanista. Un análisis de los discursos de José Ingenieros, Alfredo Palacios y Manuel Ugarte. Ponencia presentada en XII Jornadas Interescuelas de Historia, Universidad Nacional del Comahue, Bariloche, Argentina.

Dalla-Corte Caballero, G., Álvarez, G. y Prósperi, M. (2011). Socialistas y socialismo en Santa Fe. La organización que venció al tiempo. Rosario: Prohistoria.

Estévez Boero, G. (1988). Balance de los 70 años de la Reforma Universitaria. En Ministerio de Educación y Justicia de la Nación, La Reforma Universitaria, 1918-1988. Buenos Aires: Legasa.

Freidemann, S. (2017). La peronización de los universitarios como categoría nativa (1966-1973). Folia histórica del Nordeste, (29), 113-144. Recuperado de http://revistas.unne.edu.ar/index.php/fhn/article/ view/2434/2149 
González, J. V. (1945). La Universidad. Teoria y acción de la reforma, Buenos Aires: Claridad.

Graciano, O. (2008). Entre la torre de marfil y el compromiso politico. Intelectuales de izquierda en la Argentina, 1918-1955. Bernal: Universidad Nacional de Quilmes.

Halliday, F. (1970). Estudiantes del mundo, uníos. En A. Cockburn y R. Blackburn (Eds.), Poder estudiantil. Problemas diagnósticos y acción (pp. 351-399). Buenos Aires: Tiempo Nuevo.

Herrera, C. M. (2013). El intelectual como partido: Dardo Cúneo y la experiencia de Acción Socialista, Archivos de historia del movimiento obrero y la izquierda, (3), 35-58. Recuperado de http://www. archivosrevista.com.ar.ca1.toservers.com/contenido/wp-content/uploads/2015/03/N3-Herrera.pdf

Kozel, A. (2015). Estaciones del antiimperialismo rioplatense. En A. Kozel, F. Grossi y D. Moroni (Coords.), El imaginario antiimperialista en América Latina (pp. 25-51). Buenos Aires: CLACSO/Ediciones del CCC.

Manrique, N. (2009). "'Usted fue aprista!” Basespara una historia critica del APRA. Lima: CLACSO/Pontificia Universidad Católica del Perú.

Millán, M. (2013). Entre la Universidad y la politica. Los movimientos estudiantiles de Corrientes y Resistencia, Rosario, Córdoba y Tucumán durante la "Revolución Argentina" (1966-1973). (Tesis doctoral inédita). Universidad de Buenos Aires, Buenos Aires, Argentina.

Movimiento Nacional Reformista (2011). 50 años de historia de lucha. Buenos Aires: MNR.

Nieto Montesinos, J. (2000). Haya de la Torre o la politica como obra civilizatoria. México: Fondo de Cultura Económica.

Palacios, A. (1961). Nuestra América y el imperialismo. Buenos Aires: Palestra.

Pis Diez, N. (2012). La política universitaria peronista y el movimiento estudiantil reformista: actores, conflictos y visiones opuestas (1943-1955). Los trabajos y los días, (3).

Pita, A. (2004). Intelectuales, integración e identidad regional. La Unión Latino Americana y el boletín Renovación, 1922-1930. (Tesis doctoral), El Colegio de México, México, México.

Pita, A. (2009). Los homenajes a José Ingenieros y el debate en torno al papel del intelectual. Revista Complutense de Historia de América, 35.

Portantiero, J. C. (1977). Estudiantes y politica en América Latina. El proceso de la reforma universtaria (19181938). México: Siglo XXI.

Roca, D. (2006 [1918]). Reformismo y antimperialismo. Buenos Aires: Grupo Universitario.

Romero, R. (1998). La lucha continúa. El movimiento estudiantil argentino en el siglo XX. Buenos Aires: Eudeba. 
Sarlo, B. (2007). La batalla de las ideas (1943-1973). Buenos Aires: Emecé.

Sessa, L. (2013). Aprismo y apristas en Argentina: Derivas de una experiencia antiimperialista en la "encrucijada" ideológica y política de los años treinta. (Tesis doctoral inédita), Universidad Nacional de La Plata, La Plata, Argentina.

Sigal, S. (1991). Intelectuales y poder en la década del sesenta. Buenos Aires: Puntosur.

Suárez, F. M. (2018). El Partido Socialista Popular: orígenes, organización y tradiciones políticas (1972-1982). (Tesis de Maestría inédita), Universidad Nacional de La Plata, La Plata, Argentina.

Terán, O. (1991). Nuestros años sesenta. La formación de la izquierda intelectual en la Argentina. Buenos Aires: Puntosur.

Tortti, M. C. (2014). La nueva izquierda argentina. La cuestión del peronismo y el tema de la revolución. En M. C. Tortti (Dir.), La nueva izquierda argentina (1955-1976). Socialismo, peronismo y revolución. Rosario: Prohistoria.

Williams, R. (2000). Marxismo y literatura. Barcelona: Península. 